\title{
EFEITO DA ALTURA DO COMEDOURO TUBULAR SOBRE O DESEMPENHO E QUALIDADE DE CARCAÇA EM FRANGOS DE CORTE NO PERÍODO DE 28 A 42 DIAS DE IDADE
}

\author{
Victor Fernando Buttow Roll, ${ }^{1}$ Marcos Antonio Dai Prá, ${ }^{2}$ Eduardo Gonçalves Xavier, ${ }^{1}$ \\ Maria Teresa Osório, ${ }^{1}$ Erico Kunde Correa, ${ }^{1}$ Marta Helena Dias da Silveira, ${ }^{3}$ \\ Marcos Antonio Anciuti ${ }^{1}$ e Fernando Rutz ${ }^{1}$ \\ 1. Professores doutores, Universidade Federal de Pelotas. E-mail: roll2@hotmail.com \\ 2. Perdigão Agroindustrial S. A. \\ 3. Professor assistente da Universidade Tecnológica Federal do Paraná.
}

\section{RESUMO}

Com este trabalho objetivou-se verificar a influência da regulagem da altura dos comedouros tubulares no desempenho e na qualidade de carcaça de frangos de corte, e nas características microbiológicas da ração no período de 28 a 42 dias de idade. Alojaram-se 880 frangos de corte fêmeas Ross em 40 boxes (repetições) com 22 aves cada $\left(11\right.$ aves $\left./ \mathrm{m}^{2}\right)$. As aves foram submetidas a duas alturas de comedouro em dois períodos diferentes $(28$ - 35 dias de idade - comedouro alto (CAL): borda superior do comedouro a $20 \mathrm{~cm}$ do solo; comedouro baixo (CB): borda superior a $11 \mathrm{~cm}$ do solo; 36 a 42 dias de idade - CAL: borda superior a $25 \mathrm{~cm}$ do solo, $\mathrm{CB}$ : borda superior a $11 \mathrm{~cm}$ do solo). Utilizou-se o delineamento completamente casualizado, e as médias das variáveis respostas foram comparadas pelo teste ' $t$ ' de Student. No período de 28 a 42 dias de idade, não se encontraram diferenças significativas nas variáveis produtivas que justifiquem a utilização de comedouro regulado à altura do dorso das aves, conforme recomenda a grande maioria das guias de manejo. Foram encontradas menor porcentagem de gordura intermuscular nas coxas e maior de músculo nas sobrecoxas nas aves alimentadas com CB. Observou-se, também, maior quantidade de material de cama dentro dos comedouros no tratamento $\mathrm{CB}$ ao final do experimento, ainda que esta variável não tenha influenciado significativamente a qualidade microbiológica da ração.

PALAVRAS-CHAVES: Alimento, gordura, microbiologia, músculo.

\section{ABSTRACT}

\section{EFFECT OF TUBULAR FEEDER HEIGHT ON PERFORMANCE AND CARCASS TRAITS OF BROILERS FROM 28 TO 42 DAYS OF AGE}

This paper aimed to study the effect of tubular feeder height on performance, carcass traits and feed microbiological aspects of broilers from 28 to 42 days of age. Eight hundred and eighty female Ross broilers Ross were randomly allotted into 40 pens (replications) with 22 broilers each ( $\left.11 \mathrm{birds} / \mathrm{m}^{2}\right)$. Broilers were submited to two feeders height in two periods (28 to 35 days of age - high feeder (HF): superior edge $20 \mathrm{~cm}$ height; low feeder (LF): superior edge $11 \mathrm{~cm}$ height; 36 to 42 days of age - HF: superior edge $25 \mathrm{~cm}$ height; LF: superior edge $11 \mathrm{~cm}$ height). A completely randomized design was used and $t$ test was utilized to compare the treatment averages. No significant differences for performance traits from 28 to 42 days of age were observed. Therefore, the recommendation for regulating feeder height to the birds' back as in most of the poultry management guides does not seem to proceed. Birds fed in LF presented low percentage of intermuscular fat in the legs and high percentage of muscular tissue in leg quarters. Additionally, more wood shavings were found inside the feeders in LF than in HF at the end of trial, even though this variable did not influence negatively the microbiological quality of feed.

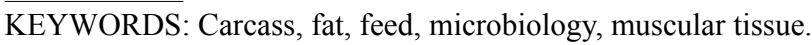




\section{INTRODUÇÃO}

Em avicultura, a grande maioria dos guias de manejo e informações técnicas para produtores recomenda ajustar os comedouros à altura do dorso das aves, visando reduzir o desperdício de ração e facilitar o acesso (AVILA et al., 1992). No entanto, existem várias razões práticas para acreditar que esta recomendação pode não ser a mais adequada para o manejo racional dos frangos de corte, incluindo: a) a realização desta prática requer tempo do produtor; b) na literatura científica são encontrados poucos trabalhos que justificam esta prática; c) a borda dos comedouros ajustada à altura do dorso das aves pode dificultar a ingestão da ração, pois as aves em seu ambiente natural buscam e ingerem alimento diretamente do solo; d) comedouros com regulagem muito alta exigem maior esforço físico das aves para alcançar o alimento, gerando desconforto; e) em aviários com cama muito alta (acima de 8,0 cm), com o avanço da idade das aves, ocorre um rebaixamento da cama, aumentando a distância do piso ao comedouro, o que pode dificultar o acesso à ração, principalmente das aves menos desenvolvidas, e aumentar a desuniformidade do lote; f) comedouros regulados na altura do dorso das aves normalmente precisam ter um nível mais elevado de ração dentro do prato para facilitar a ingestão, possibilitando contribuir para aumentar o desperdício.

A finalidade do manejo dos frangos de corte é proporcionar conforto às aves, para permitir que a qualidade e o rendimento de sua carcaça sejam ótimos, satisfazendo às exigências dos consumidores, por uma diversificação cada vez maior de seus produtos.

Uma forma de avaliar a qualidade de carcaça é verificar a sua composição tecidual, principalmente a de gordura. Hoje os consumidores preferem carcaças com maior quantidade de músculo em detrimento do tecido adiposo.

A maioria dos trabalhos publicados sobre qualidade de carcaça em frangos de corte se relaciona com nutrição. Outros trabalhos encontrados relacionados com qualidade de carcaça avaliavam materiais utilizados como cama (OLIVEIRA \& CARVALHO, 2002), densidade de aves e linhagens (MOREIRA et al., 2004), efeito do jejum pré-abate (DENADAI et al., 2002), idade da matriz (DALANEZI et al., 2005). Porém há necessidade de incrementar as informações sobre o efeito da altura do comedouro sobre o rendimento e a qualidade de carcaça em frangos de corte.

Da mesma forma, poucos estudos relacionam altura de comedouro com qualidade higiênica da ração. É sabido que os frangos de corte realizam o banho de areia, jogando material de cama por cima de seu corpo, podendo contaminar a ração presente nos comedouros. O melhor método para prevenir o crescimento de fungos é aumentar o controle de qualidade da matéria-prima e melhorar as técnicas de manejo.

Neste sentido, observou-se, na literatura científica, haver uma carência de informações relacionando a altura do comedouro com a composição microbiológica das rações.

Objetivou-se, com este experimento, verificar a influência da regulagem da altura de comedouros tubulares durante o período de 28 a 42 dias de idade, sobre o desempenho de frangos de corte, qualidade de carcaça e características microbiológicas da ração.

\section{MATERIAL E MÉTODOS}

Foram alojados, em aviário experimental, 880 frangos de corte fêmeas Ross divididos em quarenta boxes (repetições) com 22 aves cada $\left(11\right.$ aves $\left./ \mathrm{m}^{2}\right)$. Nos boxes, a cama com 10 centímetros de espessura foi de cepilho de madeira, que era diariamente revirada e alinhada. Cada boxe apresentava bebedouros lineares de água corrente tipo nipple e um comedouro tubular com capacidade para $18 \mathrm{~kg}$ de ração.

No período de um a quatorze dias todas as aves receberam ração inicial contendo $21,5 \%$ de proteína bruta e $3.000 \mathrm{kcal} \mathrm{EM} / \mathrm{kg}$, de quinze a 28 dias contendo $19,5 \%$ de proteína bruta e $3.180 \mathrm{kcal} \mathrm{EM} / \mathrm{kg}$. No período final e experimental de 28 a 42 dias de idade, as aves receberam ração de crescimento com $17,3 \%$ de proteína bruta e $3.230 \mathrm{kcal} \mathrm{EM} / \mathrm{kg}$ ração. As aves foram submetidas a duas alturas de comedouro a partir dos 28 dias de idade, conforme esquema apresentado na Tabela 1. Com a ajuda de uma trena, media-se a distância entre a parte superior da cama de maravalha e a borda superior do prato do comedouro. Foi utilizada uma densidade de 22 frangos por comedouro tipo tubular com prato de $42 \mathrm{~cm}$ de diâmetro e capacidade para $18 \mathrm{~kg}$ de ração 
TABELA 1. Esquema da regulagem da altura dos comedouros utilizados no experimento: altura $(\mathrm{cm})$ da borda superior do prato de comedouros pendulares tubulares até a cama

\begin{tabular}{ccccc}
\hline & $28-35$ dias de idade & \multicolumn{2}{c}{$36-42$ dias de idade } \\
\hline Regulagem & Alta & Baixa & Alta & Baixa \\
\hline & $20 \mathrm{~cm}$ & $11 \mathrm{~cm}$ & $25 \mathrm{~cm}$ & $11 \mathrm{~cm}$ \\
\hline
\end{tabular}

Obs.: Regulagem interna do comedouro: $4,0 \mathrm{~cm}$

Ao início do experimento, com a distribuição dos tratamentos às unidades experimentais, foi registrado o peso inicial das aves e realizada uma análise estatística, que mostrou não haver diferenças significativas entre o peso vivo das aves nos dois grupos testados $(1325,02 \mathrm{~kg}$ vs 1325, $29 \mathrm{~kg})$. As variáveis produtivas analisadas foram o consumo de ração, consumo de ração ajustado para mortalidade, o ganho de peso, a conversão alimentar, viabilidade e eficiência produtiva, conforme fórmulas a seguir. $\mathrm{O}$ cálculo do índice de eficiência produtiva foi realizado em cada tratamento pela fórmula expressa por: IEP $=\mathrm{Gmd} \times \mathrm{Vb} \times \mathrm{EA}$, em que: $\mathrm{Gmd}=$ ganho médio diário $=$ peso vivo $(\mathrm{kg}) /$ idade (dias), $\mathrm{Vb}=$ viabilidade $(\%)=100-(\%)$ mortalidade, $\mathrm{CA}=$ consumo de ração $(\mathrm{kg}) / \mathrm{ganho}$ de peso $(\mathrm{kg})$, EA $=$ eficiência alimentar $=1 / \mathrm{CA}$

Após jejum de seis horas, aos 42 dias de idade, foram abatidas duas aves representativas do peso médio de cada unidade experimental (totalizando oitenta aves) para avaliação do peso de carcaça, peso de coxa e sobrecoxa e gordura abdominal. A gordura abdominal foi considerada com o tecido adiposo contido ao redor da cloaca, da bursa de Fabricius e dos músculos abdominais adjacentes.

A dissecação das coxas e sobrecoxas foi realizada por pessoal treinado, separando-se mecanicamente (com ajuda de pinças e bisturi) cada componente tecidual. Os componentes avaliados em cada peça foram: peso da coxa e sobrecoxa, pele, gordura subcutânea, músculo, gordura intermuscular, osso e outros (tendões, cartilagens, fáscias e vasos sanguíneos).

Ao final do experimento, de toda a ração que sobrou nos comedouros foi retirada uma amostra, sempre colhendo-se cinco pontos equidistantes dentro do prato, em cada box, para a realização de análise micológica. Nesta análise foi utilizada a técnica de Pour-Plate, realizando-se quatro diluições (1:10) para cada amostra.
A partir de cada diluição, distribuíram-se os inóculos nas placas previamente esterilizadas. Em seguida, verteram-se, em ágar Sabouraud dextrose, $20 \mathrm{~mL}$ em cada placa de Petri contendo a suspensão diluída da amostra, homogeneizando-se o material através de movimentos circulares. Após, incubaram-se as placas tampadas em estufas microbiológicas em temperatura de $20^{\circ} \mathrm{C}$. Ao final da incubação, contaram-se as colônias, sendo o resultado médio de cada diluição registrado e multiplicado pelo fator da diluição. A contagem de unidades formadoras de colônias (UFC) foi realizada no quinto dia e a identificação dos fungos deu-se conforme as características macro e micromorfológicas das colônias.

De forma semelhante, a variável material de cama presente nos comedouros foi avaliada peneirando-se toda a ração existente nos comedouros ao final do experimento, utilizando-se peneiras 9 e $4 \mathrm{~mm}$ e pesando-se a quantidade de impurezas da cama existente nos pratos.

Utilizou-se o delineamento completamente casualizado, sendo as médias das variáveis respostas comparadas através do teste " $\mathrm{t}$ ".

O modelo estatístico adotado foi o seguinte:

$$
\mathrm{Y}_{\mathrm{ij}}=\mathrm{m}+\mathrm{t}_{\mathrm{i}}+\mathrm{e}_{\mathrm{ij},} \text {, em que }
$$

$\mathrm{m}=$ média observada da variável resposta;

$\mathrm{t}_{\mathrm{i}}=$ efeito do tratamento, $\mathrm{i}=1,2$.

$\mathrm{e}_{\mathrm{ij}}=$ erro experimental associado à repetição $\mathrm{j}$ $(\mathrm{j}=1,2,3, \ldots)$ no tratamento $\mathrm{i}$.

\section{RESULTADOS E DISCUSSÃO}

Não foi encontrada nenhuma diferença significativa entre os tratamentos para as variáveis de desempenho (Tabela 2). O experimento começou a partir de 28 dias de idade, porque havia a hipótese de que este seria o período crítico em que os frangos desperdiçariam proporcionalmente mais ração em função do maior volume consumido em comparação com a fase inicial das aves. No entanto, os resultados de DAI PRÁ et al. (2006) indicam que não se pode desprezar o desperdício de ração na fase inicial. Em seu estudo, os autores verificaram desperdício de 4,26 e 7,27 kg de ração nos comedouros regulados semanalmente de acordo com o crescimento das aves na altura do peito e no dorso, respectivamente, resultando numa economia de $3,01 \mathrm{~kg}$ de ração por comedouro regulado à baixa altura no período de um a 49 dias de idade. 
TABELA 2. Dados de desempenho de acordo com a altura de comedouro no período de 28 a 42 dias de idade (médias \pm erro)

\begin{tabular}{lcccccc}
\hline & \multicolumn{3}{c}{28 a 36 dias } & \multicolumn{3}{c}{36 a 42 dias } \\
\hline CAlave/dia (g) & $132,8 \pm 1,2$ & $132,4 \pm 0,9$ & NS & $190,9 \pm 1,4$ & $184,4 \pm 1,42$ & NS \\
Caj/ave/dia (g) & $132,7 \pm 1,2$ & $132,2 \pm 0,9$ & NS & $190,6 \pm 1,4$ & $184,2 \pm 1,4$ & NS \\
PV/sem (g) & $1915,5 \pm 8,4$ & $1938,6 \pm 10,0$ & NS & $2381,7 \pm 12,2$ & $2395,6 \pm 13,0$ & NS \\
GP/sem & $590,5 \pm 3,9$ & $613,3 \pm 4,4$ & NS & $466,3 \pm 5,7$ & $457 \pm 5,9$ & NS \\
GM/sem & $84,4 \pm 0,6$ & $87,6 \pm 0,6$ & NS & $66,6 \pm 0,8$ & $65,3 \pm 0,8$ & NS \\
CA/sem & $1,6 \pm 0,01$ & $1,5 \pm 0,01$ & NS & $2,9 \pm 0,02$ & $2,8 \pm 0,03$ & NS \\
IEP/sem & $343,1 \pm 4,3$ & $360,1 \pm 5,2$ & NS & $195,2 \pm 2,8$ & $197,9 \pm 3,9$ & NS \\
\hline
\end{tabular}

CAL: comedouro alto; CB: comedouro baixo; C: consumo; Caj: consumo ajustado para mortalidade; PV: peso vivo; GM: ganho médio; sem: semana; CA: conversão alimentar; IEP: índice de eficiência produtiva.

Dada a dificuldade de permanecer em pé junto aos comedouros altos, a maioria das aves faz visitas rápidas, retirando muitas vezes a cabeça de dentro dos comedouros, consumindo maior quantidade de ração de cada vez. Sempre que a ave retira a cabeça do prato do comedouro, arrasta consigo certa quantidade de ração aderida ao bico que acaba sendo desperdiçada. Esta é a explicação mais provável para o consumo de ração numericamente superior nos CAL. Dessa forma, recomenda-se, para diminuir o desperdício de ração, trabalhar com pouca ração no prato dos comedouros tubulares (lâmina de $1 \mathrm{~cm}$ de altura) regulados com a borda superior ao nível do peito das aves ou mais baixa, desde que os comedouros não fiquem encostados no solo, pois a movimentação é fator importante para que a ração desça ao prato.

$\mathrm{Na}$ Tabela 3 observa-se que os frangos manejados com CB a partir do $28^{\circ}$ dia de vida apresentaram maior quantidade de músculos na coxa e menor quantidade de gordura na sobrecoxa quando comparados com frangos manejados com CAL.

É possível que o maior esforço físico realizado pelas aves para alcançar a ração dentro dos pratos dos CAL promova maior gasto energético nesse músculo, ocorrendo, dessa forma, menor desenvolvimento das fibras. A alteração no comportamento ingestivo em virtude da altura do comedouro indicada pela frequência e duração das visitas ao comedouro) observada por ROLL et al. (2010) pode ter influência sobre a fisiologia, o metabolismo e a deposição dos nutrientes na carcaça. Um fato importante observado foi a tendência de menor quantidade de gordura abdominal, subcutânea e intermuscular, ainda que somente esta última tenha sido estatisticamente diferente nas sobrecoxas. Essas tendências são importantes comercialmente, pois coincidem com a preferência dos consumidores por carnes mais magras, contendo maior quantidade de músculo.

O abdômen é um dos principais locais de deposição de gordura no frango (MICHELAN FILHO, 1986) e pode estar diretamente correlacionado com a quantidade de gordura depositada na carcaça. Ainda que no presente experimento somente a gordura intermuscular das sobrecoxas tenha sido estatisticamente diferente, estudos para a determinação do teor de gordura da carcaça inteira mostram-se importantes, pois, segundo GAYA(2003), o excesso de gordura tem sido reconhecido como um dos principais problemas da indústria da carne de frango atual.

Outro fato importante observado foi a maior quantidade de material de cama nos $\mathrm{CB}$ ao final do experimento, o que ocorreu porque a aves realizaram o comportamento de banho. O banho se divide em três fases: primeiro a ave, em posição de descanso, esfrega-se no solo jogando material de cama por cima de seu corpo, fazendo movimentos com as patas e asas (VESTERGAARD et al., 1990). Esse comportamento ocorre de forma fragmentada, com duração média de dez segundos cada um (SMITH et al., 1993). No momento em que as aves realizam esta atividade, parte do material acaba sendo jogada para dentro dos comedouros. 
TABELA 3. Peso de carcaça e gordura abdominal e peso e composição tecidual de coxas e sobrecoxas de acordo com a altura de comedouro no período de 28 a 42 dias de idade (média \pm erro)

\begin{tabular}{|c|c|c|c|}
\hline & CAL & $\mathrm{CB}$ & Prob. \\
\hline Peso da carcaça $(\mathrm{kg})$ & $1955,4 \pm 12,1$ & $1952,3 \pm 17,0$ & NS \\
\hline Peso das coxas $(\mathrm{g})$ & $233,9 \pm 2,7$ & $234,5 \pm 2,2$ & NS \\
\hline Peso das sobrecoxas (g) & $252,8 \pm 2,8$ & $257,2 \pm 4,4$ & NS \\
\hline \multirow[t]{2}{*}{ Gordura abdominal (g) } & $30,3 \pm 1,6$ & $26,8 \pm 1,8$ & NS \\
\hline & \multicolumn{3}{|c|}{ Composição tecidual da coxa esquerda } \\
\hline Peso da coxa (g) & $112,8 \pm 1,7$ & $114,2 \pm 2,8$ & NS \\
\hline Pele $(g)$ & $10,5 \pm 0,5$ & $11,2 \pm 0,7$ & NS \\
\hline Gordura subcutânea (g) & $3,1 \pm 0,5$ & $2,7 \pm 0,5$ & NS \\
\hline Músculo (g) & $60,9 \pm 1,0$ & $61,9 \pm 2,4$ & $\mathrm{p}=0,01$ \\
\hline Gordura intermuscular (g) & $1,5 \pm 0,2$ & $1,1 \pm 0,4$ & NS \\
\hline Osso (g) & $23,8 \pm 0,6$ & $24,2 \pm 1,2$ & NS \\
\hline \multirow[t]{2}{*}{ Outros (g) } & $9,8 \pm 0,6$ & $10,4 \pm 1,0$ & NS \\
\hline & \multicolumn{3}{|c|}{ Composição tecidual da sobrecoxa esquerda } \\
\hline Peso da sobrecoxa (g) & $124,4 \pm 2,6$ & $126,0 \pm 4,3$ & NS \\
\hline Pele $(g)$ & $10,6 \pm 0,6$ & $12,6 \pm 0,7$ & NS \\
\hline Gordura subcutânea (g) & $6,8 \pm 0,7$ & $5,6 \pm 0,6$ & NS \\
\hline Músculo (g) & $79,0 \pm 2,1$ & $77,6 \pm 3,8$ & NS \\
\hline Gordura intermuscular (g) & $4,2 \pm 0,3$ & $3,8 \pm 0,6$ & $\mathrm{p}=0,02$ \\
\hline Osso (g) & $15,4 \pm 0,5$ & $16,0 \pm 0,5$ & NS \\
\hline Outros (g) & $4,7 \pm 0,5$ & $5,1 \pm 1,3$ & NS \\
\hline
\end{tabular}

CAL: comedouro alto; $\mathrm{CB}$ : comedouro baixo.

O objetivo do banho é regular a condição da plumagem, eliminando o excesso de óleo das penas (BAXTER, 1994). Além de ter uma função física, o banho também é uma necessidade comportamental (VESTERGAARD et al., 1990). Dessa forma, pode ser previsto que regularmente será incorporada uma quantidade de material de cama significativa dentro dos comedouros CB.

$\mathrm{Na}$ análise da presença de material de cama nos comedouros observaram-se, ao final de duas semanas, valores médios de $16 \mathrm{~g}$ de material de cama nos $\mathrm{CB}$, divididos de forma semelhante em duas porções de 8 g nas peneiras 9 e $4 \mathrm{~mm}$, sendo praticamente o dobro das 9,7 $\mathrm{g}$ de impurezas retidas nas duas peneiras nos CAL $(\mathrm{P}<0,05)$. Neste caso, era de se esperar que a presença de impurezas afetasse a qualidade da ração, principalmente pela presença de fungos, já que estes se encontram associados a diferentes tipos de matéria or- gânica. Por essa razão, quantificou-se a população microbiana das amostras, realizando-se um estudo sobre a presença de fungos nos comedouros. Na contagem de unidades formadoras de colônias, foram contabilizadas $15 \times 10^{2}$ Penicillium spp., $2 \times 10^{2}$ Fusarium spp. e $4 \times$ $10^{2}$ leveduras nos CAL e $6 \times 10^{2}$ Penicillium spp., $1 \times$ $10^{2}$ Fusarium spp. e $6 \times 10^{2}$ leveduras nos CB.

Apesar de não haver legislação específica sobre o número máximo de UFC de fungos que podem ser encontrados nas dietas para animais de produção, PONTE et al. (1989) consideram que valores menores do que o logaritmo de 10 na potência quatro são aceitáveis do ponto de vista higiênico. Como os valores encontrados não alcançaram o limite estipulado por PONTE et al. (1989), conclui-se que não existe problema micológico na ração ao se manejar as aves com comedouros regulados à baixa altura. 


\section{CONCLUSÃO}

A altura do comedouro não influenciou as características microbiológicas da ração, nem o desempenho de frangos de corte no período de 28 a 42 dias de idade. No entanto, foram encontradas menor porcentagem de gordura intermuscular nas coxas e maior de músculo nas sobrecoxas nas aves manejadas com comedouros baixos.

\section{REFERÊNCIAS}

AVILA, V. S.; JAENISCH, F. R. F.; PIENIZ, L. C.; LEDUR, M. C.; ALBINO, L. F. T.; OLIVEIRA, P. A. V. Produção e manejo de frangos de corte. Concórdia: EMBRAPA-CNPSA, 1992 (Documentos, 28). Disponível em: <http://www.cnpsa.embrapa. $\mathrm{br} /$ index.php?idp=Pr6i99h6q $>$.

BAXTER, M. R. The welfare problems of laying hens in battery cages, Veterinary Record, v. 134, n. 6, p. 614-619, 1994.

DAI PRÁ, M. A.; ROLL, V. F.; XAVIER, E. G.; ROLL, A. P. Avaliação do desperdício de ração e desempenho de frangos de corte submetidos a duas alturas de comedouro. In: XV CONGRESSO DE INICIAÇÃO CIENTIFICA, 15., 2006, Pelotas, RS. Anais... Universidade Federal de Pelotas, 2006. Disponível em: $<$ http://www. ufpel.edu.br/cic/2006/resumo_simples/CA/CA_00122.pdf>.

DALANEZI, J. A.; MENDES, A. A.; GARCIA, E. A.; GARCIA, R. G.; MOREIRA, J.; PAZ, I. C. L. A. Efeito da idade da matriz sobre o desempenho e rendimento de carcaça de frangos de corte. Arquivo Brasileiro de Medicina Veterinária e Zootecnia, v. 57, n. 2 , p. $250-260,2005$.

DENADAI, J. C.; MENDES, A. A.; GARCIA, R. G.; ALMEIDA I. C. L.; MOREIRA J.; TAKITA, T. S.; PAVANA. C.; GARCIA, E. A. Efectt of Feed and water withdrawal on carcass yield and breast meat quality of broilers. Revista Brasileira de Ciência Avicola, v. 4, n. 2, p. 101-109, 2002.
GAYA, L. de G. Estudo genético da deposição de gordura abdominal e de características de desempenho, carcaça e composição corporal em linhagem macho de frangos de corte. 2003. 99 f. Dissertação (Mestrado em Concentração de Qualidade e Produtividade Animal) - Faculdade de Zootecnia e Engenharia de Alimentos, Universidade de São Paulo, Pirassununga, Disponível em: <http://www.teses.usp.br/teses/disponiveis/74/74131/ tde-12042004-164232/>. Acesso em: 5 dez. 2008.

MICHELAN FILHO, T. Seleção para diminuição do conteúdo de gordura em frangos. Concórdia: Ed. EMBRAPA-CNPSA, 1986. 19 p.

MOREIRA, J.; MENDES, A. A.; ROÇA, R. O.; GARCIA, E. A.; NAAS, I. A.; GARCIA, R. G.; PAZ, I. C. L. A. Efeito da densidade populacional sobre desempenho, rendimento de carcaça e qualidade da carne em frangos de corte de diferentes linhagens comerciais. Revista Brasileira de Zootecnia. [online]. 2004, v. 33, n. 6 p. 1506-1519. Disponível em: <http://www.scielo.br/ scielo.php?script $=$ sci_arttext\&pid $=\mathrm{S} 151635982004000600018 \&$ $\operatorname{lng}=$ en $\&$ nrm $=$ iso $>$.

OLIVEIRA, M. C.; CARVALHO, I. D. Rendimento e lesões em carcaça de frangos de corte criados em diferentes camas e densidades populacionais. Ciência e Agrotecnologia, v. 26, n. 5, p. 10761081, 2002. Capturado em 05 dez. 2008. Disponível em: www. editora.ufla.br/revista/26_5/art25.PDF. Acesso em: 5 dez. 2008.

PONTE, J. G.; JORDANA J. A. J.; CAMPANERA J. M. P.; ARROYO T. R. El problema de la contaminación fúngica en la industria de piensos. Barcelona: Ed. Lucta, 1989. 199 p.

SMITH, S. F.; APPLEBY, M. C.; HUGHES, B. O. Nesting and dust bathing by hens in cages: Matching and mis-matching between behaviour and environment. British Poultry Science, v. 34, n. 1, p. 21-33, 1993.

VESTERGAARD, K.; HOGAN, J. A.; KRUIJT, J. P. The development of a behaviour system: Dustbathing in the Burmese red junglefowl. The influence of the rearing environment on the organization of dustbathing. Behaviour, v. 112, n. 1, p. 35-52, 1990.

Protocolado em: 19 dez. 2007. Aceito em: 2 jul. 2010. 